\title{
Do jornalismo esportivo ao infotretenimento: 0 caso do contrato entre Neymar Jr. e Globo como paradigma
}

\section{From sports journalism to infotainment: the case of the contract between Neymar Jr. and Globo as a paradigm}

Carlos Peres de Figueiredo Sobrinho ${ }^{1}$

Anderson David Gomes dos Santos ${ }^{2}$

Resumo: Este artigo parte do desenvolvimento teórico da Economia Política da Comunicação voltada ao Jornalismo para analisar as mudanças na cobertura esportiva midiática. Analisa-se as mudanças no jornalismo esportivo do Grupo Globo, indo das questões estruturais neste setor no conglomerado ao contrato com Neymar Júnior, vigente nos anos de 2014 e 2015. Dada a necessidade de fonte secundária não científica sobre o observável, além da revisão teórica, utilizamos o método de pesquisa documental para resgatar matérias jornalísticas que tratam das mudanças no grupo comunicacional e do contrato com o jogador de futebol. Assim, conta-se o que ocorreu, possibilitando a análise a partir do marco teórico escolhido. O fato analisado representa o ápice da transição do jornalismo tradicional para o infotretenimento na cobertura esportiva, motivado por questões relacionadas à reestruturação do sistema capitalista.

Palavras-chave: Grupo Globo; Neymar Júnior; cobertura esportiva; entretenimento; economia política da comunicação.

1 Universidade Federal de Sergipe (UFS). São Cristóvão, SE, Brasil. https://orcid.org/0000-0003-3608-1407 E-mail: carlospfs@gmail.com

2 Universidade Federal de Alagoas (UFAL). Santana do Ipanema, AL, Brasil. https://orcid.org/0000-0001-7178-5923 E-mail: andderson.santos@gmail.com 
Abstract: This paper is based on the theoretical development of a Political Economy of Communication focused on journalism studies to analyze the changes in sports media coverage. The object is the changes in sports journalism of Grupo Globo, from the structural issues of the sector in the conglomerate to the contract with Neymar Junior, in force in 2014 and 2015. Given the need for a non-scientific secondary source on the observable, in addition to the theoretical review, we used the documentary research method to rescue journalistic articles that deal with changes in the communication group and the contract with the football player. Thus, it is told what happened, enabling the analysis from the chosen theoretical framework. The analyzed fact represents the culmination of the transition from traditional journalism to infotainment in sports coverage, motivated by issues related to the restructuring of the capitalist system.

Keywords: Grupo Globo; Neymar Junior; sports coverage; entertainment; political economy of communication 


\section{Introdução}

O processo de o esporte ser tratado como entretenimento midiático está atrelado à nova etapa de mercantilização vivida nesta atividade a partir dos anos 1990, com a requalificação dos estádios a partir da Inglaterra e as exigências para realizar megaeventos esportivos. Além disso, há a interferência do modelo estadunidense de aproximar a cobertura esportiva da espetacularização, lembrando que a Copa do Mundo FIFA 1994 e os Jogos Olímpicos de Verão de 1996 foram realizados nos Estados Unidos.

No caso brasileiro, a cobertura esportiva da mídia sempre deu mais atenção ao futebol que aos demais esportes, seguindo predominantemente os cânones da prática jornalística. Entretanto, no caso do Grupo Globo, identificamos que há uma mudança a partir de 2009, momento que apresentaremos ao longo deste artigo.

O objetivo deste texto é descrever e discutir esse processo que leva o conglomerado a tratar a cobertura esportiva como entretenimento, fazendo com que o aspecto informativo seja relegado a segundo plano, o que teve como ponto culminante, em nossa análise, o contrato do Grupo Globo com o jogador Neymar Júnior, que durou de 2014 a 2015. Entende-se que o tratamento de uma possível fonte como parceiro comercial representa o ápice do infotretenimento na área, um legado que os megaeventos esportivos ajudaram a construir, mas que vai além da realização da Copa do Mundo FIFA Brasil 2014.

Para isso, partiremos do eixo teórico-metodológico da Economia Política da Comunicação (EPC) para entender como os modelos de negócio acabam por impactar no trabalho jornalístico e, consequentemente, nos critérios de noticiabilidade. Assim, trata-se aqui de investigação qualitativa, que mobiliza pesquisa bibliográfica a partir de discussão de uma Economia Política sobre o Jornalismo, assim como de trabalhos sobre as mudanças do jornalismo esportivo e da constituição de Neymar enquanto membro do star system ${ }^{3}$ da produção global de mercadorias culturais,

3 A construção de um star system, de acordo com Morin (1989), foi uma estratégia adotada na primeira metade do século XX pelos estúdios de cinema de Hollywood para alavancar as bilheterias, e que acabou copiada em diferentes países. Com o aumento do alcance da Indústria 
gerando o interesse no contrato exclusivo com o grupo comunicacional. Realizou-se também pesquisa documental em sites noticiosos como Folha de São Paulo (SABINO; GARCIA, 2014; NETO, 2016), Globo.com (MARCOS, s/d) e UOL (GLOBO, 2015) para tratar da reestruturação do setor de Esportes na Globo neste século e do contrato estabelecido com o jogador.

Para isso, fazemos uma análise histórica documental, encarando os materiais noticiosos levantados para este estudo como documentos factuais. Aqui entendemos "documentos" de uma forma ampla, indo de materiais escritos e estatísticas até elementos iconográficos que ainda não passaram por qualquer tratamento científico (GODOY, 1995). "Esses documentos são utilizados como fontes de informações, indicações e esclarecimentos que trazem seu conteúdo para elucidar determinadas questões e servir de prova para outras, de acordo com o interesse do pesquisador" (SÁ-SILVA; ALMEIDA; GIUNDANI, 2009, p. 5). Assim, "tudo o que é vestígio do passado, tudo o que serve de testemunho, é considerado como documento ou "fonte" (CELLARD, 2008, p. 296).

A análise documental é justificada por consideramos que os documentos examinados na análise descrevem melhor o processo estudado neste artigo devido às poucas produções científicas sobre o tema e à proximidade temporal do acontecimento estudado. Como adverte Cellard (2008, p. 295), muitas vezes os documentos permanecem "como o único testemunho de atividades particulares ocorridas num passado recente".

\section{O jornalismo enquanto campo de análise científica}

O produto noticioso é fruto do trabalho de uma gama de profissionais que atuam dentro de redações, todos considerados jornalistas: fotógrafos, diagramadores, editores, repórteres etc., além do pessoal de apoio (caso de motoristas e gráficos para o jornalismo impresso), entre outros. As teorias do jornalismo que tratam da produção da notícia, conhecidas

Cultural, as estrelas de cinema ganham companhia no Olimpo de outros tipos de celebridades, como músicos, aventureiros e atletas, após a profissionalização e midiatização do esporte. 
no arcabouço da teoria do newsmaking, buscam responder à questão “por que as notícias são como são?” (TRAQUINA, 2004) através de uma análise das chamadas "rotinas produtivas", que nada mais são que rotinas de trabalho.

Os teóricos do newsmaking observaram que os jornalistas precisam produzir coletivamente um noticiário em determinado espaço de tempo, assim estão sempre preocupados com o deadline. Essas teorias foram elaboradas na época em que a internet era restrita a uns poucos aficionados, acadêmicos e militares, e, portanto, seus proponentes não imaginaram que a tecnologia comprimiria de tal forma a relação entre o espaço e o tempo, que o deadline seria reduzido drasticamente.

Para vencer o desafio do deadline, as empresas jornalísticas estabelecem uma série de rotinas e um conjunto de lugares a serem cobertos, o que Tuchman (1978) chama de rede de faticidade. Esses lugares sociais são aqueles ocupados por instituições capazes de criar fatos dotados de legitimidade oficial, o que tornaria as notícias credíveis. Como consequência o campo jornalístico acabaria por reproduzir o discurso de espaços oficiais de poder: delegacias, campo jurídico, parlamentos, academia etc.

Os jornalistas estariam, assim, dentro de uma estrutura que faria com que acabassem por reproduzir o discurso do status quo. Além das rotinas, o estabelecimento de condutas profissionais e a socialização dentro da redação acabariam também por influenciar a produção das notícias, já que ajudariam a moldar os critérios de noticiabilidade e o comportamento diante de fontes.

É inegável o valor analítico e o poder explicativo das teorias do jornalismo acerca das forças que moldam o noticiário. Entretanto, a incorporação da ideologia do profissionalismo como categoria de análise nessas teorias se, por um lado, mostra como o jornalista pode usar normas de conduta para se defender de pressões indevidas de seus superiores; por outro, apaga-o como trabalhador intelectual, cujo papel é realizar a mediação entre mercado e consumidores, a função 
publicidade da informação; e entre Estado e cidadãos, a função propaganda (BOLAÑO, 2000).

A EPC, a partir de categorias marxistas como trabalho e subsunção, pode jogar luz sobre pontos cegos da teoria do jornalismo. Como afirma Lopes (2016, p. 12):

A aproximação dos dois campos, sob a égide de uma teoria marxista da comunicação poderia, se balizada na dimensão epistemológica do conflito, permitir a necessária revisão conceitual e metodológica capaz não somente de fornecer instrumentos analíticos mais próximos da realidade empírica e capazes de contribuir para a mudança social, mas também de melhor posicioná-las diante das lutas epistemológicas do campo.

O jornalista como trabalhador intelectual sempre teve seu trabalho subsumido ao capital, apesar de a própria subsunção encontrar claros limites no trabalho noticioso. Historicamente, a subsunção se dá de início a partir do momento em que o artesão passa a ser um empregado assalariado dentro das manufaturas. Há uma brusca desqualificação desse trabalhador, que não mais domina todo o processo de produção, mas apenas uma parte. É o que Marx (2013) nomeia subsunção formal ao capital, porque ainda há a necessidade de grande quantidade de trabalho vivo dentro das manufaturas. O advento da maquinaria, transformando o trabalhador em um mero operador da máquina, marca a passagem da subsunção formal à subsunção real do trabalho ao capital, pois há a substituição maciça de trabalho vivo por trabalho morto, tornando o trabalho vivo supérfluo.

O trabalho intelectual apresenta claros limites à subsunção devido à dificuldade em objetivar o elemento subjetivo desse tipo de trabalho, como aponta Bolaño (2002). O jornalista, por exemplo, faz várias escolhas em seu labor. Escolhe o ângulo das matérias, as fontes que serão entrevistadas (para além daquelas apontadas por pauteiros e editores), as perguntas que serão feitas nas entrevistas, o que fotografar durante as pautas etc. Claro, essa liberdade não é total. A linha editorial, a socialização dentro das redações e o profissionalismo servem como formas incompletas de controle. 
A partir da década de 1970, um novo regime de acumulação, que viria a substituir o Fordismo/Keynesianismo, entra em cena: o modo de acumulação flexível. Até aquele momento existia um pacto de classes entre burguesia e proletariado mediado pelo Estado, responsável também por regular a atuação dos capitais, impedindo crises sistêmicas. Devido às crises de descontentamento entre minorias e trabalhadores e ao esgotamento do sistema levando à estagflação ${ }^{4}$, a circulação de capitais é gradativamente desregulada, assim como as relações entre o trabalho e o capital (HARVEY, 2012).

Os jornalistas passam a sentir as consequências desse novo estado de coisas com a entrada da tecnologia informática nas redações: é a fase do jornalismo flexível. Os softwares de edição de texto e tratamento de fotos permitem eliminar postos de trabalho. Essa facilidade em diminuir empregos em razão da desregulamentação na relação capital/trabalho e da entrada de novas tecnologias é o que Rosso (2017) chama de flexibilidade numérica, o que leva à flexibilidade funcional. Assim, os jornalistas agora precisam ter a capacidade de preencher mais de uma função. Tal organização do trabalho aumenta a extração do que Marx (2013) chamou de mais-valia relativa.

O tempo de trabalho necessário para o jornalista produzir o suficiente para sua reprodução diminui, aumentando seu mais-trabalho, já que sua jornada não é retraída. O profissional é sobrecarregado com mais textos e pautas, tornando difícil a produção de matérias que partam da singularidade dos fatos para tratar do particular e do universal (GENRO, 1987). A chegada da internet em meados da década de 1990 vai reforçar esse quadro de flexibilização e precarização do trabalho do jornalista. Os limites à subsunção diminuem, mas não deixam de existir.

A convergência de linguagens acaba obrigando o jornalista a produzir mais notícias para diferentes meios, além de diminuir o tempo de apuração, o que gera notícias presas à pura singularidade do fato.

4 Nunes (2015, p. 6) afirma que após a crise do petróleo surgiu a estagflação, termo que se refere ao momento em que o capitalismo monopolista conseguiu que "taxas elevadas e crescentes de inflação coexistissem com taxas de crescimento do produto [interno bruto] próximas de zero ou mesmo negativas (acompanhadas de elevadas taxas de desemprego". 
A audiência das matérias passa a ser monitorada em tempo real, impactando na concorrência por verba publicitária. Sites como Google e Facebook tornam-se empresas capazes de vender publicidade direcionada com alto grau de precisão através da análise de grande quantidade de dados colhidos a partir das interações dos usuários durante a navegação.

Tal método é bem mais preciso do que a organização da grade de programação baseada no monitoramento da audiência por amostra domiciliar. Assim, a instantaneidade e as táticas de mercantilização da notícia, surgidas com o desenvolvimento da internet, acabam invadindo outros meios que concorrem com sites de redes sociais e noticiosos por publicidade. A queda do valor da publicidade causada pelo aumento da oferta na internet acaba criando a necessidade de que as empresas produzam mais com menos.

Os primeiros cortes de custos são verificados na força de trabalho, com o aumento da mais-valia relativa através do aumento da produtividade. Em seguida, há cortes nos custos com o deslocamento de profissionais, que passam a trabalhar cada vez mais de dentro da redação. Isso tem reflexo na cobertura esportiva, em que há a diminuição das idas aos estádios. Esses fatores contribuem para mudanças nos critérios de noticiabilidade e para a queda da qualidade na cobertura. Aproxima, ainda, a Ciência da Comunicação da discussão sobre a categoria do "infoentretenimento" ou "infotretenimento".

Oselame e Finger (2013, p. 64) apontam que o infotretenimento praticado no jornalismo, especialmente o esportivo, "redimensiona valores clássicos da profissão, como interesse público, objetividade, independência, legitimidade e, principalmente, uma prerrogativa fundamental do ofício do jornalista: a credibilidade", em troca da lucratividade que a notícia passa a ter como maior foco numa versão mais próxima ao espetáculo. O jornalista deixaria de exercer a função, alterando seu papel social de mediador do que é produzido, para ser um artista, não tendo necessariamente o compromisso com a verdade dos fatos.

As autoras tratam ainda de duas consequências desse padrão: proliferação de um humor desmedido e limitação da criatividade. A tentativa 
de se fazer rir ocorre muitas vezes com um humor duvidoso, com textos pobres e conteúdos escolhidos a partir de uma "cobertura de acontecimentos supérfluos", gerando uma "consequente desvalorização da notícia” (OSELAME; FINGER, 2013, p. 70-71).

Seguindo esse novo padrão de criação de notícias, que as pesquisadoras denominam como "engraçadismo", o que é produzido precisa atender à seguinte fórmula: "Uma brincadeira no texto, um trocadilho, um efeito de edição e, se possível, uma pauta que não se restrinja à notícia esportiva para que possa, dessa forma, agradar também àqueles que querem apenas passar o tempo diante da televisão" (OSELAME; FINGER, 2013, p. 71).

Assim, a pressão constante por audiência aliada à necessidade de diminuir os curtos da apuração acabam por gerar matérias sobre a vida privada dos atletas, dentro da prática chamada de caça-cliques, com conteúdo pouco informativo ou mesmo irrelevante, cujo objetivo é inflar a audiência do veículo de comunicação (FRANGE, 2016). A busca por audiência e, consequentemente, por rendas publicitárias acabaram por fazer com que sites de jornalismo esportivo publicassem "aquele material que era publicado somente por portais de fofocas ou sobre famosos" (FRANGE, 2016, p. 118).

A Globo respondeu a essas transformações a partir de mudanças internas na empresa quanto à organização dos direitos de transmissão, na nomenclatura do departamento responsável pela cobertura esportiva e na forma de apresentar o conteúdo, como veremos a seguir.

\section{Mudanças do esporte no Grupo Globo}

O futebol é um assunto que faz parte de forma constante do noticiário no Brasil desde os anos 1910, ganhando força especialmente a partir da década de 1930, com a profissionalização deste esporte e do rádio5. O

5 O primeiro governo de Getúlio Vargas (1930-1945), período conhecido como ditadura do Estado Novo, utilizou do futebol e da transmissão de rádio como formas de integrar nacionalmente e para propaganda política. Em 1931, publicou o decreto que estabelecia o modelo comercial da transmissão radiofônica. Dois anos depois, incluiu nas leis trabalhistas que jogar futebol poderia ser uma profissão, oficializando a saída do amadorismo, assim como a geração 
desenvolvimento da área de esportes no Grupo Globo está presente desde o seu tratamento no jornal impresso, mídia inicial do conglomerado, partindo em seguida para emissoras de rádio e televisão, onde se estabelece, com os produtos na internet e nas mídias móveis se beneficiando desta construção histórica.

A preocupação em transmiti-lo pela TV aberta, dada as características iniciais dessa mídia, passa pelo pool de emissoras na Copa do Mundo FIFA México 1970 até chegar à exclusividade da Rede Globo na transmissão da Copa do Mundo FIFA Espanha 1982 e da Copa União em 1987, considerado como Campeonato Brasileiro daquele ano. Além disso, os programas esportivos estão presentes nessa TV desde 1966, menos de um ano depois da inauguração da primeira concessão da rede. Ainda assim, conforme Santos (2013), o primeiro pacote de transmissão ofertado ao mercado publicitário, com quantidade de jogos por ano, só se dará a partir de 1990 e a definição de dias e horários fixos na grade de programação da Rede Globo ocorre apenas em 2001.

Desde os anos 1970, o jornalismo esportivo da emissora era parte da Central Globo de Jornalismo. O Grupo Globo cria na década de 1990 a divisão específica para tratar da aquisição de direitos de transmissão esportivos, a Globo Esportes. Quando a emissora perde os direitos de competições olímpicas de 2008 a 2014 para a Rede Record, uma série de mudanças ocorre na área, o que gera reflexos na estrutura organizativa e coincide com mudanças na forma da cobertura.

Quanto à estrutura de cobertura de eventos esportivos, em 2009 a Rede Globo criou a Central Globo de Esportes, ligada à Direção Geral de Jornalismo e Esporte (DGJE), a qual também estava submetida à Central Globo de Jornalismo, delimitando, portanto, uma diferença entre as duas áreas.

A Globo Esportes seria protagonista dois anos depois no processo de implosão do Clube dos 13, associação que representava os clubes de maior torcida do país, responsável por negociar os direitos de transmissão

de receitas. Vargas falava à população em discursos abertos no Estádio de São Januário, no Rio de Janeiro, com transmissão pela Rádio Nacional, de propriedade estatal (SANTOS, 2013). 
do Campeonato Brasileiro de Futebol, frente a uma ameaça de perda desses direitos para a Record.

Em 2015, seu diretor, Marcelo Campos Pinto, foi um dos nomes que apareceu em meio a uma megaoperação do FBI sobre corrupção no futebol mundial a partir dos contratos de vendas de direitos de transmissão de eventos esportivos, o que forçou nova alteração. O setor passaria a ser comandado por Pedro Garcia, então diretor de canais e produtos esportivos da Globosat, com as equipes da Rede Globo e da Globosat atuando em conjunto pela negociação dos direitos. A área, autônoma até então, passou a ser subordinada por um Comitê de Direitos Esportivos, formado por Carlos Henrique Schroder (diretor-geral da Rede Globo), Alberto Pecegueiro (diretor-geral da Globosat) e Jorge Nóbrega (membro do Conselho de Administração do Grupo Globo) (GLOBO, 2015).

Quanto ao conteúdo, em 2007 a Rede Globo fez uma opção de exibir o Globo Esporte - programa esportivo diário de 30 minutos - para toda a rede a partir do Rio de Janeiro. Além de reproduzir a transmissão centralizada dos seus telejornais, colocou-se uma bancada no estúdio, com apresentação de Tino Marcos e Glenda Kozlowski. Ainda assim, Marcos (2018) já indicava mudança na linguagem:

O nosso jeito de fazer caminhou para textos mais conversados e coloquiais. É cada vez mais a janela do entretenimento ampliando o seu espaço. A janela do jornalismo continua ali, mas no esporte as pessoas têm hoje essa percepção de que o entretenimento também é uma maneira muito correta de se trabalhar o noticiário esportivo.

Em 2009, a descentralização na transmissão do Globo Esporte retornou. É neste processo que Tiago Leifert aparece como apresentador e editor do Globo Esporte São Paulo. Com formação jornalística nos Estados Unidos, onde a profissão é mais técnica e os esportes estão mais próximos do espetáculo na cobertura midiática, há “mudanças no padrão tecno-estético das matérias esportivas da emissora, com maior presença do humor e de outras formas de narrar histórias, para além dos padrões telejornalísticos construídos pela própria Rede Globo de Televisão" (SANTOS, 2013, p. 147). 
O produto primordial para esta alteração foi o programa Central da Copa, que ocorria após os jogos da Copa do Mundo FIFA África do Sul 2010 ou durante o Jornal da Globo. Ele foi repetido na Copa América e nos dois megaeventos da FIFA realizados no Brasil, em 2013 e 2014. O programa tinha participação de um auditório para comentar as partidas, com a presença de alguns dos nomes da cobertura esportiva da emissora como convidados.

Em análise comparativa sobre as versões do Rio Grande do Sul e de São Paulo do Globo Esporte, a cobertura esportiva televisiva passaria a ser classificada como infotretenimento, pois:

Ao privilegiar os fatos omnibus, o programa coloca a notícia esportiva em segundo plano e assume a postura de que é mais importante provocar o riso, entreter e descontrair do que propriamente informar. É o fenômeno do engraçadismo: a função essencial do jornalista já não é mais selecionar, tratar e apresentar as notícias em um pacote ao mesmo tempo atraente e informativo, mas, antes disso, divertir a audiência. Privilegiando a piada em detrimento da informação, o jornalista se torna uma espécie de humorista. Assim, a notícia não só fica prejudicada como, muitas vezes, simplesmente não se faz presente (OSELAME; FINGER, 2013, p. 67, grifos das autoras).

Leifert seguiu para a área de entretenimento do conglomerado em julho de 2015, mas houve nova alteração estrutural nos esportes em outubro de 2016. O Grupo Globo criou uma área independente do jornalismo para cuidar da produção de conteúdos esportivos na Rede Globo de Televisão, na Globosat, no Globoesporte.com e no Sportv. com, reunida sob comando de Roberto Marinho Neto. Essa decisão redundou em cerca de 40 demissões de jornalistas no ano seguinte, incluindo o então diretor da Central Globo de Esportes, Renato Ribeiro, com Marinho Neto acumulando o cargo (NETO, 2016).

O novo departamento também passou a ser "responsável pela aquisição de direitos esportivos, pesquisa de mercado e soluções multiplataforma" (NETO, 2016), acontecimento que reforça o que apontamos no trecho anterior sobre os desafios para o jornalismo na contemporaneidade. 


\section{0 contrato do Grupo Globo com Neymar}

Ao tratar de jornalismo esportivo é necessário entender que o acesso da imprensa aos jogadores se transformou nas últimas duas décadas, com um maior controle das assessorias de imprensa. Esse também é um elemento a ser considerado para a busca de novos caminhos para uma cobertura informativa.

A Globo Esportes passou a utilizar do fato de adquirir com exclusividade os direitos de transmissão para exigir prioridades na cobertura esportiva. Santos (2013), por exemplo, relata que Marcelo Campos Pinto chegou a mandar e-mails aos clubes no segundo semestre de 2012 para que as mídias do conglomerado tivessem mais facilidades na cobertura diária dos times brasileiros.

Assim, equipes do Esporte Espetacular cobriram os bastidores das partidas finais do Campeonato Brasileiro daquele ano do rebaixado Palmeiras e do campeão Corinthians. $\mathrm{O}$ mesmo se deu na relação com a Confederação Brasileira de Futebol (CBF) quanto à cobertura da seleção brasileira, com um caso exemplar durante a Copa do Mundo FIFA Brasil 2014.

Antes mesmo de o torneio começar, o técnico Luiz Felipe Scolari dera entrevista exclusiva ao Jornal Nacional no mesmo dia da convocação para a Copa. Quanto ao mundial, Lisboa (2014, p. 5) descreve que houve controle da oferta de material da CBF para os jornalistas, que encararam uma série de restrições, com exceção do Grupo Globo:

Para isto, além de condicionar a um credenciamento prévio a liberação para a cobertura da imprensa à seleção brasileira durante a Copa do Mundo, a organização controlou todos os contatos de jornalistas com jogadores. Na maior parte das vezes, a oportunidade de entrevista que os jornalistas possuíam eram as coletivas, que têm todas as suas regras definidas pela CBF. [...]. Além disso, a CBF oferecia aos jornalistas, através de um canal no YouTube, vídeos mostrando um pouco dos bastidores da preparação dos atletas da seleção e, através de seu site e perfis em redes sociais, outras informações que acabavam pautando o noticiário da seleção brasileira. O único veículo que parecia ter maior liberdade na sua cobertura da seleção foi a TV Globo, que possuía um histórico de boa relação 
com a CBF e que, além disso, foi a detentora, no Brasil, dos direitos de transmissão da Copa do Mundo de 2014.

Rocco Júnior (2015) defende que esta relação chegou a prejudicar a preparação da seleção brasileira, com diversas ações que chegaram a atrapalhar treinos, caso da chegada de helicóptero do apresentador Luciano Huck no gramado durante treinamento para gravar um quadro de seu programa. O autor afirma que: "A emissora atuou livremente nas dependências do Centro de Treinamento da CBF fazendo, com total autonomia, as ações que interessavam a ela, Rede Globo, sem preocupação alguma com os treinamentos e o foco dos atletas brasileiros para tão importante competição" (ROCCO JÚNIOR, 2015, p. 166).

Essa imposição do grupo para privilegiar o acesso às fontes de notícia esportiva existe especialmente enquanto parceiro comercial das organizadoras dos eventos. "Em razão do envolvimento das emissoras de televisão não apenas na transmissão dos eventos esportivos como na sua própria promoção, torna-se difícil distinguir as fronteiras entre o jornalismo e a valorização do espetáculo" (OSELAME; FINGER, 2013, p. 65). É a partir dessa premissa que queremos analisar o contrato entre Neymar e o Grupo Globo, garantido privilégios no acesso ao jogador Neymar Júnior em 2014 e 2015.

Segundo Sabino e Garcia (2018), a emissora defendeu que o contrato "referia-se a participações especiais de Neymar em programas e em campanhas da emissora, bem como ao uso de conteúdos audiovisuais produzidos pelo jogador". Até janeiro de 2019 o site oficial do jogador (neymaroficial.com) seguia na plataforma Globo.com.

Ainda de acordo com os jornalistas, Neymar participou no período anterior à Copa de diferentes programas da Rede Globo: Domingão do Faustão (em maio); Esporte Espetacular (em maio, com entrevista exclusiva); Caldeirão do Huck (em sua casa em Barcelona, às vésperas da Copa); Fantástico (entrevista em julho). Depois as aparições foram menos frequentes: Domingão do Faustão (em duas homenagens a amigos); Esporte Espetacular (em dezembro, em Barcelona); Globo Esporte 
(num quadro gravado em Praia Grande-SP); e na novela A Regra do Jogo (SABINO; GARCIA, 2018).

É importante entender que Neymar era o principal jogador do Brasil na Copa, sendo atração para distintas marcas, com mais aparições na publicidade no Brasil. Como afirma Silva (2017, p. 3, tradução nossa), ao tratar da primeira entrevista dele ao Esporte Espetacular:

Esta iniciativa jornalística visa aumentar os índices de audiência durante a Copa do Mundo, transmitida pela Rede Globo, rede de televisão brasileira. A exaltação de Neymar é uma estratégia narrativa de agendamento esportivo para personificar o jogo de exibição e, posteriormente, a Copa do Mundo de 2014. Neymar é invocado como a estrela da equipe nacional, aquela que poderia dar ao povo brasileiro o título de campeão mundial - as imagens mostram o jogador cantando o hino nacional, marcando um gol e passando, torcendo. ${ }^{6}$

Helal, Lisboa e Mostaro (2015) destacam a reportagem sobre a vida de Neymar no Jornal Nacional, que fechou a série sobre todos os jogadores convocados para a Copa. Nesse caso, além de ter sido a última, o que dá atenção especial, teve 9 minutos, 3 a mais que a média da realizada com os outros atletas do Brasil.

Já Oliveira, Rodrigues e Araújo (2015, p. 16), ao analisarem as matérias veiculadas pelo Globoesporte.com um mês antes do início do Mundial, observam que não houve nenhuma informação negativa sobre o jogador no período observado. Pelo contrário, elas "enalteceram a posição de Neymar como grande ídolo do Brasil e o possível herói na conquista do hexacampeonato mundial".

O anúncio do contrato colocou em xeque a cobertura jornalística do Grupo Globo porque justamente a partir de 2016, com o término do acordo, alguns comentaristas e narradores passaram a criticar Neymar. Basta lembrar da cobertura do futebol masculino nos Jogos Olímpicos

6 Do original "This initiative of the news story aims at increasing ratings during the World Cup, broadcast by Rede Globo, Brazilian television network. The exaltation of Neymar is a narrative strategy of the sports agenda so as to personify the exhibit game and, later, the 2014 World Cup. Neymar is invoked as the star of the national team, the one who could give the Brazilian people the world champions title - images show the player singing the national anthem, scoring a goal and passing, cheering". 
de 2016, com o jogador evitando dar entrevistas em determinados momentos do torneio; da polêmica de 2018 com Walter Casagrande Júnior, que chamou o jogador de mimado, tendo uma resposta do pai de Neymar pelas mídias sociais; e da cobertura do conglomerado na Copa do Mundo FIFA Brasil 2018, que também criticou Neymar por exagerar na reação ao sofrer faltas.

Mas é preciso recordar também que, ao menos na Copa do Mundo FIFA Brasil 2014, com um mal futebol jogado pela seleção em boa parte do torneio, Neymar foi um dos poucos que conseguiram se sobressair. Além disso, o atleta estava ausente na derrota de 7 a 1 para a Alemanha nas semifinais, por ter sofrido uma lesão na partida anterior.

Lisboa (2014, p. 9) relata, inclusive, que o jogador foi escolhido pela CBF após o 7 a 1 para dar entrevista coletiva, de maneira a acalmar o clima de cobranças por parte dos jornalistas que faziam a cobertura da Seleção:

Após dois dias seguidos de entrevistas muito tensas, repletas de cobranças diretas aos membros da seleção brasileira após a maior derrota da história da seleção brasileira, o que imperou na entrevista de Neymar foi um clima de cordialidade em relação ao entrevistado.

Esta cordialidade foi evidenciada nas manifestações de carinho manifestadas ao jogador pelos jornalistas, e que teve seu ápice na efusiva salva de palmas que foi direcionada a Neymar ao final da entrevista.

O interesse por famosos é um fenômeno próprio da cultura de massa, de acordo com Morin (1977), para quem as celebridades formam o Olimpo Moderno. Assim, "olimpianas e olimpianos são sobre-humanos no papel que eles encarnam, humanos na existência que levam" (MORIN, 1977, p. 106). O autor considera que "a imprensa de massa, ao mesmo tempo que investe os olimpianos de um papel mitológico, mergulha em suas vidas privadas a fim de extrair delas a substância que permite a identificação" (MORIN, 1977, p. 106-7). Essa identificação e inserção no imaginário coletivo acabam por fazer com que o público acompanhe cada passo desses indivíduos. 
Por outro lado, a atenção que esses olimpianos galvanizam torna-os extremamente atrativos à indústria da publicidade. Olimpianos assinam contratos vultosos com marcas de materiais esportivos, suplementos alimentares e o que mais possam vender. Entretanto, precisam estar em evidência não só pelos seus feitos esportivos, no caso dos atletas, mas também por suas vidas fora de campo para entrarem no imaginário coletivo. "A estrela é uma mercadoria total: não há um centímetro de seu corpo, uma fibra de sua alma ou uma recordação de sua vida que não possa ser lançada no mercado" (MORIN, 1979, p. 76). Logo, seu cotidiano, incluindo feitos, alegrias, tristezas e relacionamentos amorosos, deve ser encarado como mercadoria.

Assim, essas celebridades precisam criar constantemente pseudoeventos que são acontecimentos fabricados, não espontâneos, construídos unicamente para serem divulgados pelos meios de comunicação (BOORSTIN, 1961). Parte do cotidiano dos olimpianos serve para potencializar a atenção do público. Os sites de redes sociais, como Instagram, Facebook e Twitter, em conjunção com as mudanças no jornalismo contribuíram para que esses atletas fabriquem pequenos pseudoeventos ao longo do dia, que são replicados por sites jornalísticos em sua busca desesperada por audiência.

O contrato entre Neymar e Globo parece inusitado, mas segue um processo lógico dentro da constituição do que chamamos de jornalismo flexível, em que as fronteiras entre entretenimento e jornalismo estão cada vez mais tênues, mesmo em áreas mais tradicionais do jornalismo como a política (BRANTS, 1998). Entretanto, a Globo, com esse contrato, eleva essa tendência a um patamar inimaginável, transformando um jogador, que é uma fonte valiosa para seus jornalistas, em parte de seu star system. Um arranjo em que a lógica comercial acaba abalando alicerces do jornalismo ao quebrar tabus no relacionamento entre fontes e jornalistas. Ao mesmo tempo que a beneficia frente à concorrência por contar com o ídolo do momento, que, como afirmam Brito e Rego (2019, p. 9), sua presença ou ausência "em determinado evento 
transmitido pelos meios de comunicação afetaria o conteúdo da mensagem e a forma como ela é recebida pelo grande público".

É preciso considerar que a transmissão televisiva de grandes eventos esportivos como a Copa do Mundo e as Olimpíadas caminhou de mãos dadas com a profissionalização de atletas e o surgimento do marketing esportivo, como pontua Smit (2007). Nos anos 1970, empresas de material esportivo como Puma e Adidas disputavam contratos de exclusividade no uso de material esportivo com atletas como Pelé, Beckenbauer e Cruyff. Entretanto, esses atletas eram parte do Olimpo esportivo, coberto pelos diferentes meios de comunicação, e não integrantes do star system de conglomerados da Indústria Cultural.

A Globo, no decorrer de sua história, usou a tática do star system para aumentar a audiência de suas novelas e de outros programas de sua grade, mas a incorporação de um Olimpiano do mundo esportivo à sua constelação de estrelas cria conflitos de interesses entre as partes de entretenimento e jornalismo da emissora.

Como observa Gans (1980), o relacionamento entre fontes e jornalista é visto como um cabo de guerra em que muitas vezes ambos têm interesses diferentes. O jornalista quer extrair informação de interesse público enquanto as fontes querem promover fatos de seu interesse. $\mathrm{O}$ contrato entre Globo e Neymar é uma acomodação comercial entre os interesses de ambos, que só pode ser explicado a partir das estratégias de adaptação do grupo a uma nova realidade de mercado. Nesse contrato, não há nenhum cuidado com o interesse público.

\section{Considerações finais}

Procuramos demonstrar ao longo deste artigo, tanto do ponto de vista de discussão teórica quanto utilizando do exemplo do Grupo Globo, as alterações históricas nos preceitos do jornalismo, especificamente no caso da cobertura esportiva, que passa a se enquadrar cada vez mais sob o conceito de "infotretenimento".

Mais que um legado exclusivo do ciclo de megaeventos esportivos realizados no Brasil de 2007 a 2016, dois realizados pela FIFA (Copa 
das Confederações 2013 e Copa do Mundo 2014), as mudanças na cobertura do futebol pelo principal conglomerado comunicacional no país representam um processo desenvolvido ao longo de duas décadas do século XXI. Como buscamos demonstrar, as alterações no padrão de transmissão acompanham outras transformações estruturais no conglomerado comunicacional, deixando claro a importância de garantir a exibição dos principais torneios de futebol e a prioridade dada ao entretenimento em termos de conteúdo.

Nesse processo, o caso de Neymar representa o ápice dos problemas que surgem em casos que as fontes viram parceiras comerciais, suscetíveis a pressões por benefícios na cobertura jornalística. Ao mesmo tempo, estas fontes conseguem uma melhor "defesa" por parte dos meios de comunicação, cuja crítica não pode ocorrer. Afinal, quanto melhor for o jogador, mais oportunidades de conteúdo exclusivo por parte dos meios de comunicação da empresa. Não é por coincidência que contratos deste tipo são tratados sob sigilo.

Os estudos da Economia Política da Comunicação possibilitam analisar o processo histórico do desenvolvimento da apropriação mercadológica da comunicação e da cultura sob o modo de produção capitalista, onde estão inclusos tanto o trabalho cultural do jornalista quanto o que se refere ao futebol e a sua possibilidade de acumulação de riqueza. Desatrelar a análise a estes fatores é deixar de apresentar apontamentos fundamentais para as mudanças observadas em nosso estudo.

\section{Referências}

BOLAÑO, C. Indústria Cultural, Informação e Capitalismo. São Paulo: Hucitec/Pólis, 2000.

BOLAÑO, C. Trabalho Intelectual, Comunicação e Capitalismo. A Reconfiguração do Fator Subjetivo na Atual Reestruturação Produtiva. Revista da Sociedade Brasileira de Economia Política, Rio de Janeiro, n. 11, p. 53-78, dez. 2002.

BRANTS, K. Who's Afraid of Infotainment? European Journal of Communication, Londres, v. 13, n. 3, p. 315-335, 1998.

BRITO, F. de C.; REGO, E. Presença de Neymar: mídia, esporte-espetáculo e a produção de sentidos sobre a Seleção brasileira nas transmissões dos jogos do Brasil na Copa 
do Mundo de 2014 pela TV Globo. In: CONGRESSO BRASILEIRO DE CIÊNCIAS DA COMUNICAÇÃO, 41, Joinville. Anais... São Paulo: Intercom, 2018.

BOORSTIN, D. J. The Image: A Guide to Pseudo-Events in America. Nova York: Vintage, 1961.

CELLARD, A. A análise documental. In: POUPART, J. et al. A pesquisa qualitativa: enfoques epistemológicos e metodológicos. Petrópolis: Vozes, 2008. p.295-317.

GANS, H. J. Deciding What's News: A Study of CBS Evening News, NBC Nightly News, Newsweek and Times. Nova York: Vintage Books, 1980.

GENRO, A. O segredo da pirâmide. Para uma Teoria Marxista do Jornalismo. Porto Alegre: Tchê, 1987.

GODOY, A. S. Pesquisa qualitativa: tipos fundamentais. Revista de Administração de Empresas, p. 20-29, 1995.

FRANGE, M. B. S. N. A Produção do Jornalismo Esportivo na Internet. Curitiba: Appris, 2016.

GLOBO afasta Marcelo Campos Pinto, executivo para esportes. Máquina do Esporte, São Paulo, 06 nov. 2015. Disponível em: http://maquinadoesporte.uol.com.br/artigo/ globo-afasta-executivo-para-esportes-marcelo-campos-pinto_29344.html. Acesso em: 25 abr. 2019.

HARVEY, D. Condição Pós-Moderna. São Paulo: Loyola, 2012.

HELAL, R.; LISBOA, F. A.; MOSTARO, F. F. R. Copa de 2014 e idolatria: narrativas sobre o jogador Neymar antes do Mundial. In: MARQUES, J. C. A Copa das Copas? Reflexões sobre o Mundial de Futebol de 2014 no Brasil. São Paulo: Edições Ludens, 2015. p. 175-189.

LISBOA, F. A. Reflexões sobre o compromisso público da imprensa a partir de uma coletiva de Neymar no período da Copa do Mundo. In: CONGRESSO BRASILEIRO DE CIÊNCIAS DA COMUNICAÇÃO, 37, 2014, Foz do Iguaçu. Anais... Foz do Iguaçu: Intercom, 2014.

LOPES, R. S. Prefácio. In: DOURADO, J. L.; LOPES, D. M. M. da S.; MARQUES, R. da S. Economia Política do Jornalismo: tendências, perspectivas e desenvolvimento regional. Teresina: EDUFPI, 2016. p. 9-12.

MARCOS, T. In: MEMÓRIA Globo. Globo Esporte: Esporte como Entretenimento e Interatividade. s/d. Disponível em: http://memoriaglobo.globo.com/programas/esporte/ programas-esportivos/globo-esporte/esporte-como-entretenimento-e-interatividade.htm. Acesso em: 25 abr. 2019.

MARX, K. O Capital. Crítica da Economia Política. Livro 1. O Processo de Produção do Capital. São Paulo: Boitempo, 2013.

MORIN, E. Cultura de Massas no Século XX: o Espírito do Tempo. Neurose. Rio de Janeiro: Forense Universitária, 1977.

MORIN, E. As Estrelas. Mito e Sedução no Cinema. Rio de Janeiro: José Olympio, 1989.

NETO de Roberto Marinho assume o controle da área de esporte da Globo. Folha de S. Paulo, São Paulo, 6 out. 2016. Disponível em: http://wwwl.folha.uol.com.br/ 
esporte/2016/10/1820618-neto-de-roberto-marinho-assume-o-controle-da-area-de-esporte-da-globo.shtml. Acesso em: 25 abr. 2019.

NUNES, A. J. A. A análise marxista ajuda a compreender a crise atual do capitalismo. Revista de Direito da Faculdade de Guanambi, Guanambi, v. 1, n. 1, out. 2015.

SANTOS, A. D. G. A consolidação de um monopólio de decisões: a Rede Globo e a transmissão do Campeonato Brasileiro de Futebol. 263 f. Dissertação (Mestrado em Ciências da Comunicação). Programa de Pós-Graduação em Ciências da Comunicação, Universidade do Vale do Rio dos Sinos, São Leopoldo, 2013.

OLIVEIRA, D. R. de; RODRIGUES, A. M. da S.; ARAÚJO, D. M. E. de. O grande nome do Brasil na Copa: abordagem do site Globoesporte.com sobre o ídolo Neymar Jr. FIEP BULLETIN, Foz do Iguaçu, v. 85, p. 1-18, 2015.

OSELAME, Mariana; FINGER, Cristiane. Entre a Notícia e o Infoentretenimento: um modelo nacional de jornalismo esportivo imposto aos programas locais. Ciberlegenda, Rio de Janeiro, v. 29, n. 2, p. 61-73, dez. 2013.

ROCCO JÚNIOR, A. Brasil $1 \times 7$ Alemanha: O Dia em que a Comunicação a Favor do Esporte Goleou o Esporte a Favor da Comunicação. In: MARQUES, J. C. A Copa das Copas? Reflexões sobre o Mundial de Futebol de 2014 no Brasil. São Paulo: Edições Ludens, 2015. p. 149-174.

ROSSO, S. D. O Ardil da Flexibilidade. Os Trabalhadores e a Teoria do Valor. São Paulo: Boitempo, 2017.

SÁ-SILVA, J. R.; ALMEIDA, C. D.; GUINDANI, J. F. Pesquisa documental: pistas teóricas e metodológicas. Revista Brasileira de História ๒ Ciências Sociais, v. 1, n. 1, p. $1-15,2009$.

SABINO, A.; GARCIA, D. Por exclusividade, Globo contratou Neymar no ano da Copa de 2014. Folha de S. Paulo, São Paulo, 19 fev. 2018. Disponível em: https://wwwl.folha. uol.com.br/esporte/2018/02/por-exclusividade-globo-contratou-neymar-no-ano-da-copa-de-2014.shtml. Acesso em: 25 abr. 2019.

SILVA, F. I. C. da. Neymar, hero of children. J. Phys. Educ., Maringá, v. 28, n. 2810, p. 1-10, 2017.

SMIT, B. Invasão de Campo: Adidas, Puma e os Bastidores do Esporte Moderno. Rio de Janeiro: Zahar, 2007.

TRAQUINA, N. Teorias do Jornalismo: Porque as Notícias São Como São. Florianópolis: Insular, 2004.

TUCHMAN, G. Making News: A Study in the Construction of Reality. Nova York, Londres: The Free Press, 1978. 


\section{Sobre os autores}

Carlos Peres de Figueiredo Sobrinho - Pós-doutorando no Programa de Pós-Graduação em Comunicação da Universidade Federal de Sergipe (UFS) e secretário-geral da ULEPICC-Brasil (União Latina de Economia Política de Informação, Comunicação e Cultura-Brasil). Doutor em Sociologia pela Universidade Federal de Pernambuco (UFPE). No presente artigo, o autor concebeu e redigiu a parte que trata do Jornalismo a partir do ponto de vista da Economia Política da Comunicação e de como o jornalismo esportivo vem sendo afetado pelas mudanças tecnológicas e nas rotinas de trabalho. Também concebeu e redigiu os trechos que dizem respeito às relações entre profissionalização do futebol, marketing esportivo e jornalismo. Por fim, participou do trabalho de revisão do artigo.

Anderson David Gomes dos Santos - Professor da Unidade Educacional Santana do Ipanema/Campus Sertão da Universidade Federal de Alagoas (UFAL) e presidente da ULEPICC-Brasil (capítulo Brasil da União Latina de Economia Política de Informação, Comunicação e Cultura). Doutorando no Programa de Pós-Graduação em Comunicação da Universidade de Brasília. No presente artigo, o autor participou da concepção do desenho da pesquisa, da coleta e interpretação dos dados realizados na pesquisa documental presente no segundo e no terceiro tópicos, da discussão teórica específica sobre o conceito de infotretenimento, da redação do manuscrito e da revisão do texto.

Data de submissão: 26/04/2019

Data de aceite: 06/03/2020 